Revista de Journal of Integrated
GESTÃO COSTEIRA Integrada COSTALZONE MANAGEMENT

\title{
Situação ecológica, socioeconómica e de governança após a implementação do primeiro plano de ordenamento no Parque Marinho Professor Luiz Saldanha (Arrábida, Portugal): I - informações e opiniões dos pescadores *
}

\author{
Yorgos Stratoudakis@, ${ }^{\mathrm{a}}$; Flavio Fernández ${ }^{\mathrm{a}}$; Miguel Henriques ${ }^{\mathrm{b}}$; João Martins ${ }^{\mathrm{b}}$, Rogelia Martins ${ }^{\mathrm{a}}$
}

\begin{abstract}
Resumo
O Parque Marinho Professor Luiz Saldanha (PMLS - Arrábida, Portugal) foi criado em 1998 e está regulado por um plano de ordenamento desde 2005. Este estudo apresenta os resultados de um inquérito que recolheu informações e opiniões de pescadores do PMLS sobre a situação ecológica, socioeconómica e de governança 4-7 anos após a implementação faseada das regras nesta área marinha protegida (AMP). As 31 perguntas sobre o sistema social-ecológico e algumas perguntas auxiliares foram presencialmente respondidas em entrevistas individuais por 23 pescadores do PMLS (cerca de um terço dos licenciados) aleatoriamente escolhidos. As informações sobre a actividade pesqueira são utilizadas para formar indicadores de estado e de tendência para parâmetros ecológicos. As opiniões relacionadas com a interacção com outros utentes, as regras do PMLS e instituições associadas formam indicadores socioeconómicos e de governança considerados relevantes para qualquer AMP. Os resultados são comparados com dados oficiais de actividade pesqueira no porto de origem (Sesimbra) e com informações de literatura publicada. No geral, a caracterização da pesca do PMLS com base nas respostas ao inquérito foi reveladora de uma maior complexidade do que anteriormente reconhecida para esta pequena frota; os resultados para os indicadores ecológicos no PMLS genericamente apontam para ausência de mudança, mas são inconclusivos, dado a ausência de padrões claros nas respostas e algumas incongruências com outras fontes de informação. Os resultados para os indicadores socioeconómicos e de governança são claros no registo maioritário de desalento, mas difusos no registo das causas e propostas de solução. Esta análise é complementada pelo estudo de Stratoudakis et al., (2015) sobre as percepções de outros utentes do PMLS relativamente à mesma temática, aonde também se cruzam os resultados dos dois inquéritos. O objectivo conjunto destes trabalhos é apoiar a avaliação da eficácia de gestão no processo da primeira revisão do plano de ordenamento do PMLS e a iniciação de um plano de monitorização longitudinal focando em metodologias participativas.
\end{abstract}

Palavras-chave: AMP, Pescarias, Monitorização Participativa, Questionário, Avaliação de Eficácia de Gestão

\section{Abstract}

Ecological, socioeconomic and governance conditions after the implementation of the first spatial plan in the Prof. Luiz Saldanha Marine Park (Arrábida, Portugal): I - Fisher information and opinions

The Prof. Luiz Saldanha Marine Park (PMLS - Arrábida, Portugal) was created in 1998 and is regulated by a spatial plan since 2005 (POPNA). The present study shows results from an inquiry that collected information and opinions of PMLS fishers

\footnotetext{
@ Corresponding author, to whom correspondence should be addressed. e-mail: <yorgos@ipma.pt>

a IPMA, Instituto Português do Mar e da Atmosfera IP, Avenida de Brasília s/n; 1449-006; Lisboa, Portugal.

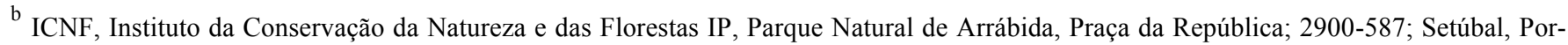
tugal.
}

Submission: 23 DEC 2014; Peer review: 8 FEB 2015; Revised: 18 FEB 2015; Accepted: 22 FEB 2015; Available on-line: 24 FEB 2015

This article contains supporting information online at http://www.aprh.pt/rgci/pdf/rgci-571_Stratoudakis_Supporting-Information.pdf
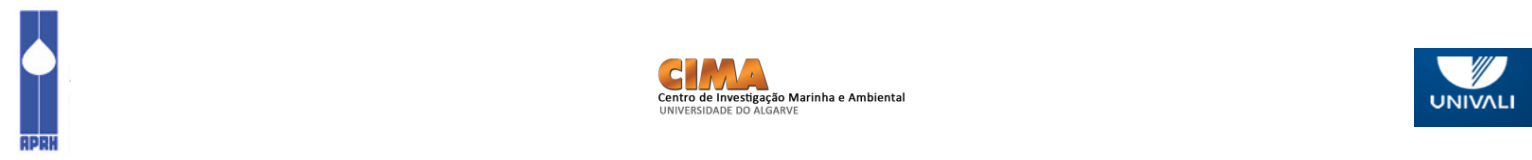
on the ecological, socio-economic and governance conditions 4-7 years after the phased introduction of regulation in this marine protected area (MPA). The 31 questions about the social-ecological system and some auxiliary questions were responded by 23 fishermen (skippers of a third of the $<7 \mathrm{~m}$ fishing vessels from Sesimbra allowed to operate in the Park) in individual interviews. Information on fishing activity is used to construct state and trend indicators for ecological variables (mean CPUE for target species, size of biggest target specimen caught in a year, number of bycatch species, number of vessels fishing at the outer limits of the MPA, etc.). Opinions related to the interaction with other users, the PMLS rules and associated institutions form socioeconomic and governance indicators considered relevant for any MPA (number of fishers affected by POPNA introduction, number of fishers known to seek PMLS license, perceived value of fishing boat and MPA license, prioritization of conflicts, etc.). The results are compared with official data of fishing activity in the fishing port of origin, Sesimbra (number of vessels and characteristics, number of landing trips, quantities and values landed daily by species and vessel) and with literature information. Overall, the characterization of the fishing activity within the PMLS based on the questionnaire replies reveals more complexity than previously reported for this small fishing fleet. The already known distinction between the smaller "aiolas" (older, wooden boats $<4 \mathrm{~m}$ with low engine power and no mechanical support for gear lifting) and the larger "botes" (newer, PVC boats, 5-7 m length, with bigger engine power and mechanical gear lifting support) is further accentuated by demonstration that "aiolas" are exclusively operating within the Park using lines and having significant lower CPUEs than the larger "botes" that also use nets and pots and in most cases simultaneously operate both within and outside the Park. The ecological results appoint to an absence of change for most indicators and a non-significant decline in target species abundance. However, these results do not depict increases in relative abundance for hake, white seabreams and red mullet that are observed in the PMLS daily landings per vessel and supported by independent observations either at larger scales (hake) or within the PMLS (white seabreams) or can be explained by modifications in the PMLS fishing regulations (red mullet). The results on the socioeconomic and governance indicators are clear in the demonstration of pessimism, but diffuse in appointing to causes or possible solutions. Although the majority does not want their descendents to relate to fishing and for themselves prefer to return to the pre-POPNA situation, they also recognize a value in the MPA license, know of people that want to acquire it and consider co-management with the MPA authority as the best way to manage the fishery. Official data on small scale fishing vessel registers from continental Portugal confirm that the number of PMLS vessels reduced in the period 2006-2014 almost the double of the national median in that period (41\% vs 22\% reduction), however this reduction has only partly led to vessel decommissioning (mainly small "aiolas"; the entry of few new and more potent vessels has actually led to a net increase in total engine power of small fishing vessels at Sesimbra compared to the year of POPNA implementation. This analysis is complemented by the study of Stratoudakis et al. (2015) on perceptions of other PMLS users with respect to the same issues. The joint objective of these studies is to support the management effectiveness evaluation underway in the process of revision of POPNA and the initiation of a longitudinal monitoring plan for the PMLS, using participative methodologies.

Keywords: MPA, Fisheries, Participatory Monitoring, Questionnaire, Management Effectiveness Evaluation

\section{Introdução}

O Parque Marinho Professor Luiz Saldanha (PMLS) foi o primeiro Parque Marinho a ser criado em Portugal continental em 1998 (Decreto Regulamentar N. ${ }^{\circ}$ 23/98) ao longo da costa da Península de Setúbal. Esta concretização legislativa surgiu 33 anos após as primeiras iniciativas para a criação de um "parque nacional submarino" na zona de Sesimbra (CPAS 1965a, b) e 22 anos depois da criação do Parque Natural da Arrábida (PNA - Decreto Lei N. ${ }^{\circ}$ 622/76) na parte terrestre da serra de Arrábida. O PNA foi criado com o intuito de proteger esta zona de elevado valor ecológico, cultural e paisagístico do aumento da intensidade da pressão demográfica e do crescimento urbano e industrial na região metropolitana de Lisboa-Setúbal. O PMLS surgiu como extensão do PNA para o mar, numa área de $53 \mathrm{~km}^{2}$ ao longo de $38 \mathrm{~km}$ de linha da costa (com o limite exterior a cerca de 1 milha da costa, em profundidades entre os 30 e os $100 \mathrm{~m}$ ). O ordenamento actual do PMLS, incluindo o zonamento com áreas de proteç̧ão total, parcial e complementar (Figura 1) com as respectivas regras de uso, foi estabelecido com o Plano de Ordenamento do Parque Natural de Arrábida publicado em 2005 (POPNA, Resolução de Conselho de Ministros N. ${ }^{\circ}$ 141/2005 de 23 de Agosto), embora apenas tenha sido totalmente consolidado em 2009 após uma fase de transição onde as restrições referentes à pesca profissional foram entrando em vigor de forma faseada.

Os objectivos do PMLS listados no POPNA são a preservação da elevada biodiversidade marinha da zona (Henriques et al., 2007); a promoção da recuperação das pradarias locais de fanerogâmicas marinhas (Cunha et al., 2014); o estímulo à investigação científica aplicada à conservação, a informação, sensibilização e educação ambientais; a adaptação das normas gerais de emissão de efluentes à capacidade do meio receptor; a promoção do turismo da natureza e das actividades económicas tradicionais de base regional como a pesca com linhas e anzóis. Este último objectivo traduz a intenção genérica do POPNA de beneficiar o desenvolvimento sustentável e o bem-estar das populações locais, juntamente com a promoção da conservação. Todavia, a introdução do plano foi demorada e contestada na fase da apresentação pública e os conflitos dos utentes com a entidade gestora e entre eles foram 


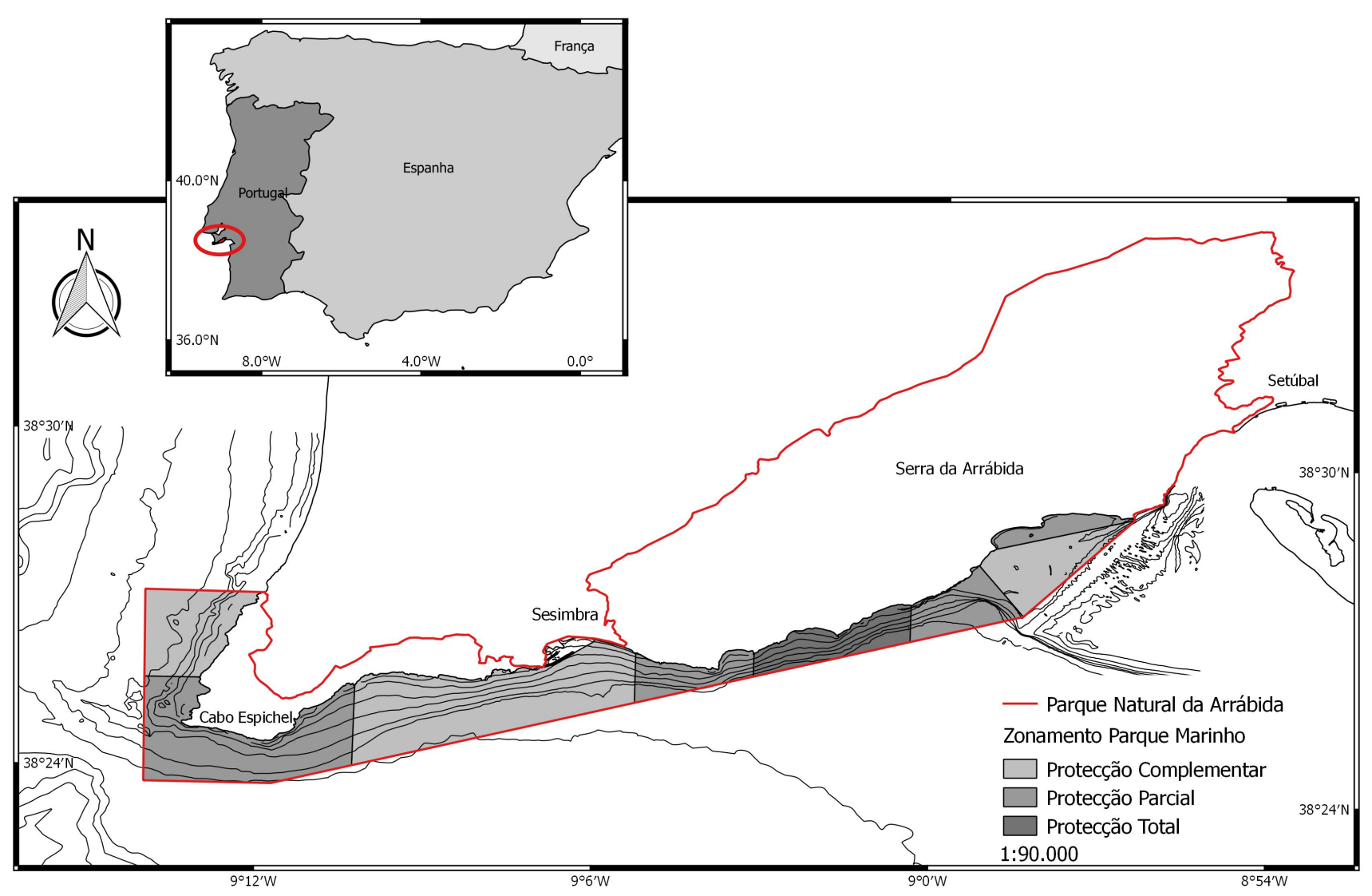

Figura 1 - Localização da área de estudo (Península de Setúbal) no contexto da Península Ibérica e zonamento do Parque Marinho Prof. Luiz Saldanha.

Figure 1 - Study area (Setúbal peninsula) location in the geographic context of the Iberian Peninsula and spatial zonation of the Prof. Luiz Saldanha marine park.

acesos e mantiveram-se após a implementação (Carneiro, 2011; Vasconcelos et al., 2012).

A contestação foi maior no caso da pesca comercial, uma vez que na área do PMLS havia longo histórico de uso por embarcações de Sesimbra e Setúbal (Cruz, 1966; Cabral et al., 2008; Ramos, 2009; Horta e Costa et al., 2013a, b). O decreto regulamentar de 1998 proibiu a pesca com ganchorra e a apanha de bivalves com escafandro autónomo na área do PMLS. Também na altura ficou prevista a possibilidade de estabelecimento de outros condicionalismos específicos ao exercício da pesca profissional e lúdica, incluindo a fixação de um número máximo de embarcações a operar na área do PMLS, dando prioridade às comunidades locais dependentes da pequena pesca. Com a implementação do POPNA em 2005, a frota de pesca com licença para operar no PMLS ficou reduzida a embarcações de Sesimbra com menos de 7 metros de comprimento total, removendo deste espaço embarcações maiores do mesmo porto (principalmente embarcações polivalentes entre 7-9 $\mathrm{m}$ e algumas maiores embarcações de cerco) e embarcações de portos vizinhos (principalmente de Setúbal).

O objectivo do presente estudo é caracterizar o sistema social-ecológico complexo do PMLS resultante da interacção da pequena pesca com esta AMP (Ostrom, 2009; McClanahan et al., 2009; Pollnac et al., 2010) depois da entrada em vigor do seu plano de ordenamento, adaptando para tal uma metodologia genérica desenvolvida no âmbito do projecto MAIA (Áreas Marinhas Protegidas no arco Atlântico; http://www. maia-network.org). Os temas são divididos entre assuntos ecológicos, socioeconómicos e de governança, com indicadores específicos para avaliar o estado actual ou a tendência recente (mas ao contrario do expert judgement utilizado por Batista et al., 2011, aqui a estimação dos indicadores é directamente baseada nas respostas dos utentes). O exercício é desenvolvido através de inquéritos e inclui o registo de informações e opiniões dos pescadores com licença para pescar no PMLS (presente trabalho) e as percepções de outros utentes do PMLS sobre os mesmos temas (Stratoudakis 
et al., 2015). O objectivo geral do conjunto destes trabalhos é apoiar a avaliação da eficácia de gestão no processo da primeira revisão do plano de ordenamento do PMLS, com base em metodologias participativas (por isto, ambos os documentos estão escritos em Português e submetidos numa revista com livre acesso online).

\section{Materiais e Métodos}

O desenvolvimento desta metodologia no âmbito do projecto MAIA teve um objectivo duplo: primeiro, apoiar a avaliação de eficácia de planos de gestão em AMPs isoladas através do contacto repetido no tempo com um painel de informantes (ver Yasué et al., 2010 para exemplo deste tipo de estudo longitudinal e Pomeroy et al., 2005 para o raciocínio subjacente a avaliações de eficácia de planos de gestão); segundo, potenciar estudos comparativos entre sistemas através da observação de padrões de semelhanças e diferenças na interacção pequena pesca/AMP em diferentes áreas (ver Jentoft et al., 2012 para exemplo desta comparação entre AMPs e Coll et al., 2014 para comparações semelhantes em escalas espacio-temporais mais alargadas).

\section{i) Inquérito}

Para construir o questionário foram inicialmente definidas 15 perguntas sobre assuntos ecológicos, socioecónomicos e de governança do sistema do PMLS e da sua interacção com a pequena pesca, que foram consideradas relevantes para a avaliação da eficácia de gestão em qualquer AMP (Pomeroy et al., 2004; Pomeroy et al., 2005). Estas perguntas são todas direccionais, apontando para o sentido considerado positivo na tendência temporal em qualquer AMP, independentemente dos objectivos específicos da criação, as regras de uso, a dimensão da área ou a duração do processo (ver Informação de Suporte: 1 - Perguntas genéricas na base do inquérito). Com base nestas 15 perguntas genéricas foram criadas perguntas específicas (uma ou mais para cada assunto), de modo que as respostas pudessem constituir um indicador quantitativo (de estado ou de tendência) para cada propriedade do sistema e que, através do seu uso repetido, se pudessem tirar ilações sobre a evolução do sistema (ver também Batista et al., 2011, Leleu et al. 2012, e Santos et al., 2012 para raciocínio similar e Stratoudakis et al., 2015 para a definição de perguntas específicas para os restantes utentes do PMLS).

No caso do questionário para os pescadores com licença da AMP os indicadores foram criados tendo em conta o conhecimento e condições de pesca locais, procurando principalmente obter indicadores de estado através de estimadores baseados no desenho de amostragem (Davis and Wagner, 2003). Para cada propriedade do sistema ecológico, tentou-se identificar um indicador familiar aos pescadores (i.e. uma variável com interesse ou facilmente quantificada por eles), pedindo uma estimativa para um período recente e uma comparação com os últimos 4-5 anos (numa escala Likert de 5 níveis: muito inferior; inferior; igual; superior; muito superior). Por exemplo, para a propriedade de biodiversidade do PMLS foi pedido para cada arte de pesca uma estimativa do número total de espécies capturadas no ultimo ano (incluindo as espécies sem valor comercial) em intervalos que variaram de $<5$ espécies até $>30$ espécies e depois foi perguntado como este número se comparava com os últimos 4-5 anos. As perguntas ecológicas foram desenvolvidas ao nível dos métiers (principais artes, usadas numa época do ano para determinadas espécies alvo), assim as informações e comparações ecológicas foram requeridas ou ao nível da arte (dimensão, frequência de uso por semana dentro e fora do PMLS, etc.) ou ao nível da espécie alvo (captura numa semana normal de trabalho, peso máximo de exemplar capturado no último ano, etc.).

No total foram desenvolvidas 5 perguntas para caracterização da actividade pesqueira e 12 perguntas ecológicas. No caso das propriedades socioeconómicas e de governança foram também desenvolvidos alguns indicadores de estado (e.g. "quantos projectos científicos relacionados com o PMLS conhece (nos últimos 4-5 anos), em quantos participou e de quantos teve conhecimento dos seus resultados?"), mas houve também várias perguntas de ordenação de opções (e.g. "ordena, em preferência decrescente, o regime de gestão que na sua opinião garantiria a pesca mais sustentável dentro do PMLS: regras UE (PCP - Política Comum de Pescas); regras nacionais (DGRM Direcção Geral de Recursos Naturais, Segurança e Serviços Marítimos); regras PMLS (ICNF - Instituto da Conservação da Natureza e das Florestas); cogestão (ICNF e pescadores); pescadores"). Nas perguntas de ordenação, em vários casos foi incluída uma opção aberta, enquanto que no cumprimento das regras e nos problemas de gestão pesqueira houve também perguntas abertas para registar problemas e sugestões dos pescadores. No total foram desenvolvidas 9 perguntas socioeconómicas e 10 de governança, identificando também alguns indicadores de tendência para avaliar o estado de propriedades-chave comparativamente à sua situação 4-5 anos antes (aproximadamente o período desde a entrada em pleno funcionamento dos condicionalismos espaciais do plano de ordenamento).

Para além destas 31 perguntas sobre o sistema socialecológico, foram incluídas no questionário algumas perguntas sobre o inquirido, a clareza e possível utilidade do questionário. Todas as perguntas foram inicialmente desenvolvidas em inglês, no contexto da colaboração de equipa internacional do projecto MAIA, e depois foram traduzidas para português para aplicar no PMLS. Depois da tradução, o questionário foi testado com dois colaboradores com grande ligação com a 
comunidade piscatória portuguesa e de Sesimbra para aconselhar sobre o melhor método de formular cada pergunta e os termos mais apropriados a usar. $\mathrm{Na}$ ficha do questionário um preâmbulo introduziu os objectivos e componentes do estudo no âmbito do projecto MAIA, indicando também a garantia do anonimato dos inquiridos.

\section{ii) Amostragem}

O questionário foi desenhado para ser respondido por pescadores da frota com licença de pesca no PMLS. Na data de realização do inquérito (verão de 2012) este universo era constituído por 67 embarcações de Sesimbra, todas com menos de $7 \mathrm{~m}$ de comprimento total, mas mesmo assim com alguma heterogeneidade entre botes e aiolas (ver Informação de Suporte: 2 Caracterização da frota do PMLS). O inquérito foi efectuado de Julho a Setembro de 2012, simultaneamente com o trabalho de campo para o inquérito dirigido aos outros utentes do PMLS (ver Stratoudakis et al., 2015). Foram entrevistados 23 pescadores que representam $34 \%$ do total dos pescadores com licença do PMLS na altura do estudo (ver Informação de Suporte: 3 - Representatividade da amostragem). Todos os questionários foram respondidos em formato de entrevista que durou entre 30 e 120 minutos (dependendo do detalhe nas respostas do entrevistado, da necessidade de esclarecimentos com perguntas adicionais do entrevistador e da vontade do entrevistado de falar em outros assuntos relacionados com as perguntas) e ocorreu sempre numa sala isolada, na presença exclusiva do inquirido e do entrevistador. Os entrevistadores foram os dois primeiros autores, procurando seguir o mesmo formato de entrevista. $\mathrm{O}$ inquérito estava sempre visível ao entrevistado, que podia observar as respostas que estavam a ser registadas para cada pergunta. O guião da entrevista era condicionado pela ordem das perguntas, mas para todas as situações que uma resposta extrema ou uma informação atípica era fornecida, havia oportunidade de iniciar curtos diálogos sobre o assunto. As entrevistas não foram gravadas mas foram tirados apontamentos, nomeadamente para registar frases específicas ou informações adicionais. A escolha dos inquiridos foi aleatória (baseada na disponibilidade para o dia e hora de entrevista ou no encontro na área do porto) e todos os contactados aceitaram participar. Todavia, em três casos o inquérito não foi realizado por falta de comparência e só num destes casos a entrevista foi realizada posteriormente. A idade dos inquiridos variou entre os 28 e os 71 anos (média de 50 anos), sem diferenças significativas entre pescadores de botes e aiolas (Cabral et al., 2008 indicam que os pescadores de aiolas são geralmente de maior idade de que os dos botes). $\mathrm{O}$ contacto mínimo do pescador com o sistema ecológico do PMLS foi de 7 anos, sendo em média de 30 anos e a máxima de 58 anos.

\section{iii) Dados e análise}

Para além dos dados resultantes dos inquéritos, foram também utilizados dados oficiais da DGRM para caracterização da actividade pesqueira e de desembarques para embarcações com $<7 \mathrm{~m}$ de comprimento total e licenciadas a exercer actividade profissional de pesca. Para comparar a evolução da frota no PMLS com o resto do país desde a entrada em vigor do POPNA, foram utilizados registos anuais de número de embarcações, arqueação bruta, potência de motor e comprimento médio nos 32 principais portos de pesca em Portugal continental no período 2006-2014. A análise incluiu portos com registo de embarcações licenciadas tanto para o mar como para águas interiores, mas só foram considerados os dados referentes às embarcações licenciadas para operar no mar. Para analisar a evolução de desembarques (em quantidade e valor) no PMLS, foram utilizados os registos diários por espécie para a frota do PMLS durante o período 2005-2013. É conhecido que esta informação tem várias limitações, como a contaminação dos desembarques para cumprir a regra dos 100 dias (principalmente com espécies pelágicas), a fuga à lota (principalmente para espécies mais valiosas) e o facto dos desembarques de botes incluir também capturas provenientes fora do Parque (que é impossível de discriminar). Em qualquer caso, os desembarques em lota representam por ano aproximadamente o valor global da frota do PMLS (estimativa baseada em informação fornecida pelos pescadores no inquérito), não sendo assim um valor de pescado desprezível. Procedendo também a análise por espécies ou grupos de espécies e utilizando médias de CPUEs por maré, procurámos minimizar os efeitos acima mencionados, no pressuposto de ausência de padrões sistemáticos ao longo do tempo na fuga à lota ou na repartição da captura por espécie dentro e fora do PMLS.

Os resultados do questionário e restantes dados foram codificados e analisados utilizando o software R (versão 3.1 - R Core team 2014). As perguntas ecológicas preliminares foram utilizadas para caracterizar a pesca no PMLS, enquanto que as perguntas de cada secção foram separadas em indicadores de estado (i.e. situação actual) e indicadores de tendência (i.e. evolução da situação ao longo dos 4-5 anos até a data do inquérito). Algumas variáveis ecológicas tiveram de ser consideradas no nível do métier ou da espécie alvo, criando assim algumas situações de pseudo-replicação. O carácter ordinal das respostas na escala Likert foi mantido numa escala numérica natural, na qual a resposta de ausência de mudança foi codificada como zero (ver Informação de Suporte: 4 - Método de análise de respostas ordinais na escala Likert e respectivos resultados). Para as respostas dadas sob a forma de intervalo de valores quantitativos, foi considerada a média do intervalo. Foram 
utilizados testes não paramétricos para explorar diferenças significativas na distribuição de amostras (emparelhadas ou não, utilizando o estatístico $W$ do Wilcoxon signed rank test ou rank sum test respectivamente) ou a associação entre amostras emparelhadas (através do estatístico Rho do Spearman rank correlation test).

\section{Resultados}

\section{i) A pesca no PMLS}

Os 23 pescadores que responderam ao inquérito identificaram cumulativamente o uso de 45 artes de pesca (utilizadas em simultâneo ou em períodos alternados do ano) com 57 espécies ou grupos de espécies como alvo (de 17 taxa distintos: 12 teleósteos, 3 moluscos cefalópodes, 1 crustáceo e 1 peixe cartilagíneo). Com base nestas respostas, é possível distinguir 15 métiers (Tabela 1) operados por embarcações com licença do PMLS. Alguns destes métiers foram descritos só para a área dentro do PMLS (e.g. pesca com toneira para choco - Sepia oficinalis e lula - Loligo sp.) ou só fora do PMLS (e.g. pesca de tresmalho para tamboril - Lophius sp. e raias - Raja sp.), mas a maioria dos métiers é praticada tanto dentro como fora do PMLS. Dos 17 taxa identificados como alvo, o mais comum foi o choco com 14 pescadores de tresmalho e toneira a defini-lo como principal alvo (no caso do tresmalho só para os primeiros quatro meses do ano). O segundo alvo mais comum foi o polvo (Octopus vulgaris) a ser identificado por 10 pescadores, maioritariamente de covos mas também de piteira e palangre, o terceiro foi a lula (por 7 pescadores de toneira) e quarto o linguado (Solea sp. por 5 pescadores de tresmalho).

Comparando as 17 espécies ou taxa da Tabela 1 com a lista das 10 espécies mais desembarcadas em lota pelas embarcações do PMLS ao longo de 2011 em peso e valor (dados DGRM não apresentados), nota-se que das espécies mais abundantes nos desembarques anuais não constam na Tabela 1 a cavala (Scomber colias, $1 .{ }^{a}$ espécie mais desembarcada pela frota do PMLS), o carapau (Trachurus trachurus, 3. espécie mais desembarcada) e o carapau negrão (Trachurus picturatus 10. ${ }^{a}$ espécie mais desembarcada). Destas três espécies, só a cavala consta na lista das 10 espécies mais valiosas $\left(7^{\mathrm{a}}\right)$ o que é consistente com a definição dos alvos dos pescadores em função do valor e não da abundância das espécies. Da lista das espécies na Tabela 1 não constam na lista dos mais abundantes ou valiosos a lagosta (Palinurus sp.), a moreia (Muraena helena), o tamboril, a língua (Dicologlossa cuneata), o besugo (Pagellus acarne) e o salmonete (Mullus surmuletus). A maioria destas espécies foi referida como alvo só por um pescador (o salmonete por dois e o besugo por três), o que é consistente com uma menor representação nos desembarques anuais cumulativos do PMLS. As três espécies mais importantes em 2011 (polvo, choco e lula, juntamente a perfazer $64 \%$ do valor total da primeira venda em lota das embarcações do PMLS) são também as espécies mais referidas como alvo na amostra, que perfazem $54 \%$ das pescarias identificadas nos inquéritos.

Dos 23 inquiridos, 14 afirmaram pescar só dentro do PMLS, 1 praticamente só fora e 8 tanto dentro como fora (alguns deles em simultâneo, principalmente com covos). Há uma diferença muito significativa na probabilidade de pescar dentro do PMLS para aiolas e restantes embarcações (Wilcoxon test: $W=110, p=0.001$ ); todas as aiolas e três embarcações intermédias (4-6m) sem alador declararam só pescar dentro do PMLS, podendo assim dizer-se que o grau de utilização do PMLS (parcial vs total) distingue na prática a operação dos maiores botes mecanizados com as restantes embarcações do PMLS. Só as maiores embarcações com alador (e em vários casos com mais de um tripulante) têm autonomia para se afastar do PMLS e capacidade de alar artes maiores ou em vários locais durante a mesma maré. Apesar destas diferenças espaciais, não houve diferenças significativas no número de artes utilizadas por embarcação (de 1 a 4, com mediana de 2 e média de 2,2) ou no esforço potencial: a maioria dos inquiridos assumiu pescar 4-5 vezes numa semana sem problemas de tempo, havendo também casos que só saem 1-2 vezes (emprego complementar) ou mesmo todos os dias que o mar permite. Todavia, o número de dias com vendas em lota para cada embarcação do PMLS em 2011 variou entre 27 e 209, com a média nos 125 dias (ou 2.3 saídas por semana) e com uma diferença marginalmente significativa entre aiolas e botes $(W=693, p=0,049)$ de cerca de 18 dias de menos pesca por ano para as aiolas (medianas de 117,5 e 136 dias respectivamente).

\section{ii) Indicadores ecológicos}

Dividindo a captura total estimada para uma semana de pesca sem interferências de mau tempo pelo número médio de marés nesta mesma semana típica, obtém-se uma estimativa de captura por unidade de esforço (CPUE) para cada espécie alvo por pescador do PMLS. Esta CPUE é considerada um indicador de estado ecológico da AMP (indicador de abundância de espécies focais), juntamente com o tamanho máximo capturado para cada espécie alvo (indicador de composição demográfica). A Figura 2a visualiza a relação da CPUE com o peso do maior exemplar capturado no último ano para cada espécie referido por cada entrevistado. A correlação significativa entre as duas variáveis (Spearman's rank correlation test: $R h o=0,54 ; p<0,001$ ) aponta para alguma coerência interna nas respostas dos pescadores, apesar da grande variabilidade entre espécies (peso máximo de maior exemplar varia entre $0,3 \mathrm{~kg}$ para o salmonete e $45 \mathrm{~kg}$ para a corvina) e embarcações (CPUE média de espécie alvo por maré 
Tabela 1 - Definição de métiers (i.e. combinação de arte de pesca, época do ano e espécies alvo) com base nas respostas ao inquérito pelos pescadores do PMLS. O campo PMLS identifica se o métier descrito opera Dentro ou Fora do Parque.

Table 1 - Métier definition (i.e. combination of fishing gear, season and target species) based on the replies of the questionnaire by PMLS fishers. The column PMLS indicates whether the métier is operated within (D) or outside $(F)$ the Park area.

\begin{tabular}{c|c|c|c|c|c}
\hline Arte de pesca & Característica & Dimensão & Espécies (ou Taxa) & Época & PMLS \\
\hline Covos & & $60-1500$ & Polvo & D e F \\
\hline Piteira & & NA & Polvo & D \\
\hline Toneira & & NA Choco e Lula & Choco & Jan-Abr \\
\hline Tresmalho & & $30-36$ panos & D e \\
\hline & & $30-36$ panos & Linguado, Lingua & Mai-Dez & D e F \\
\hline & & 8 panos & Lagosta & Jan - Abr & D \\
\hline Emalhar & $60 \mathrm{~mm}$ & $24-26$ panos & Salmonete & D e F \\
\hline & $80 \mathrm{~mm}$ & $23-24$ panos & Robalo & D e F \\
\hline Palangre & $220 \mathrm{~mm}$ & $86-40$ panos & Pescada e Besugo & F \\
\hline & Fino & 300 anzóis & Tamboril e Raias & D e F \\
\hline & Fino & $350-500$ anzóis & Dourada & Out-Dez & D e F \\
\hline & Fino & 500 anzóis & Corvina & Jun - Set & F \\
\hline & Grosso & 500 anzóis & Safio & Jun - Dez & D \\
\hline & Grosso & 550 anzóis & Moreia e Polvo & D e F \\
\hline
\end{tabular}
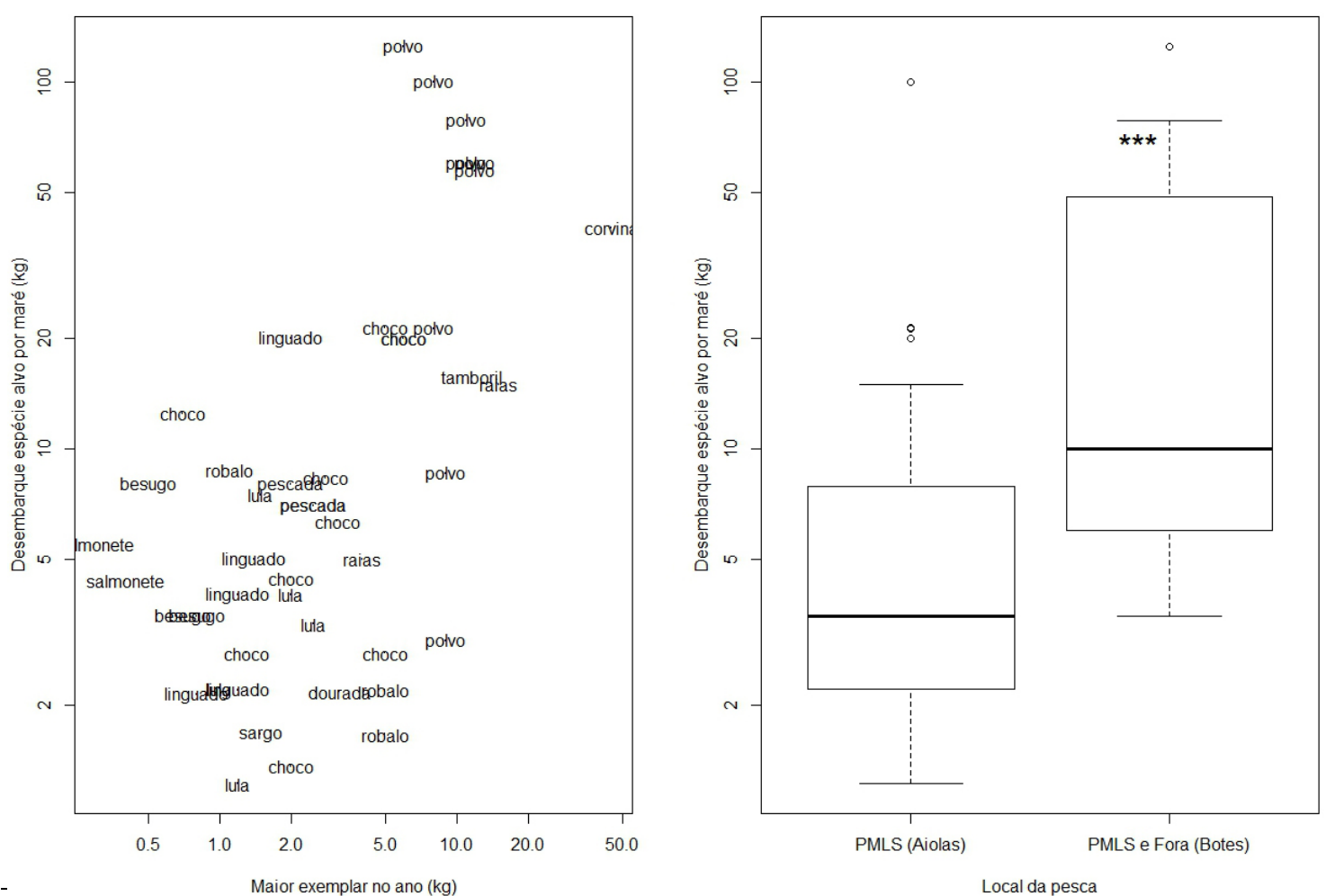

Figura 2 - Relação entre o maior exemplar da espécie alvo capturado no último ano e a captura média da espécie por maré (esquerda, gráfico em escala logarítmica) e distribuição da captura da espécie alvo por maré para embarcações que operam totalmente e parcialmente no PMLS (direita, gráfico de caixa e bigodes). Asteriscos indicam diferença altamente significativa na distribuição $(p<0,001)$.

Figure 2 - Relationship between largest specimen of target species caught in the last year and mean catch of target species by fishing trip (left, in logarithmic scale) and distribution of target species catch by trip for vessels operating always inside vs both inside and outside the PMLS (right, box and whiskers plot). Asteriscs indicate highly significant difference in distribution of CPUE $(p<0.001)$. 
varia entre 1,2-125 kg). Esta variabilidade em CPUE está em grande medida relacionada com a dimensão das embarcações (aiolas vs botes) que se reflecte bem no grau de utilização do PMLS para a sua actividade: a Figura $2 b$ mostra uma diferença significativa na CPUE das espécies alvo entre embarcações que utilizem totalmente (aiolas) ou parcialmente (botes) o PMLS para a sua actividade ( $W=465,5 ; p<0,001)$, com significativamente maiores capturas para as maiores embarcações que utilizem parcialmente o PMLS. Esta diferença é também significativa para o valor dos desembarques (considerando o valor médio da primeira venda em lota para cada espécie em 2012) por maré $(W=421,5 ; p=0,011)$, mas não para o peso máximo ( $W=353,5 ; p=0,406)$.

Outros indicadores de estado ecológico obtidos pelas respostas dos pescadores sobre a sua actividade são: a frequência de observação de artes e embarcações nas fronteiras externas do PMLS (indicador de efeito spillover da AMP), o número de espécies sem interesse comercial capturados (indicador de biodiversidade) e a frequência de captura de exemplares da espécie alvo perto do tamanho máximo registado (indicador de proporção de maiores peixes). A maioria dos pescadores inquiridos (15 dos 20 que responderam a esta pergunta, $75 \%$ ), vêm diariamente artes e/ou embarcações nas imediações do PMLS, com um pescador a assumir que nunca vê, um a assumir que vê quinzenalmente e três semanalmente. $\mathrm{O}$ número de espécies sem interesse comercial capturadas ao longo do último ano é muito dependente da arte, com as redes de tresmalho e de emalhar $(60$ e $80 \mathrm{~mm})$ a serem as artes que mais espécies capturam (maioria identificou o intervalo 2130 espécies), sendo mais variável para o palangre e sempre menor (maioria a identificar $<5$ espécies) para os covos, a toneira e a rede de emalhar de $220 \mathrm{~mm}$ de malhagem. A frequência de encontro de espécimes perto do tamanho máximo foi maioritariamente muito raro (28/57, 49\% só anualmente), mas 11/57 indicaram encontrar semanalmente, principalmente para espécies alvo das redes de emalhar.

Para os indicadores de estado acima descritos, indicadores de tendência equivalentes foram obtidos através das respostas sobre a percepção da evolução de cada indicador nos últimos 4-5 anos (ver Informação de Suporte: 4 -Método de análise de respostas ordinais na escala Likert e respectivos resultados). Em 4 dos 5 indicadores a moda está situada na percepção de ausência de mudança temporal. Só no caso da abundância das espécies alvo a moda está situada na percepção de alguma deterioração, mas mesmo assim a diferença não é significativamente diferente com uma distribuição resultante da normal padrão centrada na ausência de mudança (estatístico $k=54 \%$ ). Comparando estas percepções com os dados de desembarques por embarcações do PMLS no porto de Sesimbra durante o período 2005-2013 (Figura 3), verifica-se que as espécies alvo com padrões de aumento consistente neste período são a pescada, os sargos (Diplodus sp.) e, eventualmente, o salmonete. Para as restantes espécies sem evidência de tendência neste período, comparando o valor do CPUE em 2005 e 2013, só no caso da lula existe uma indicação de diminuição, enquanto que para a maioria das outras espécies os valores em 2013 são superiores aos registados em 2005.

Com base na pergunta sobre espécies que não sejam alvos e cuja abundância mudou muito no último ano, há mais indicações de aumento (11) do que de declínio (4). Todavia, a maioria dos aumentos é relacionada com espécies pelágicas (cavala, carapau negrão, boga Boops boops e pilado - Polybius henslowii) ou de espécies que utilizam muito pouco o PMLS no seu ciclo de vida (corvina e tamboril), sendo que só o aumento dos equinodermes (principalmente estrelas do mar) pode ter um significado ecológico local. Das espécies cuja abundância aparentou diminuição foram indicadas a faneca (Trisopterus luscus), o judeu (Coris julis), o pampo (Balistes capriscus) e o lavagante (Homarus gammarus). Finalmente, das espécies raras observadas, destaque para o registo do mero (Epinephelus marginatus) por 2 pescadores e do reconhecimento da captura de algumas espécies exóticas provavelmente de origem mais tropical (num caso o pescador informou que tinha entregue o exemplar a uma Universidade). Em relação às espécies não alvo (ver Informação de Suporte: 5 - Desembarque de espécies não alvo) os dados dos desembarques confirmam tanto o aumento muito substancial da captura de peixes pelágicos (nomeadamente cavala e boga), como a diminuição do desembarque da faneca, mas demonstram que estas alterações correspondem a um período mais alargado de tempo e não ao ano antes do inquérito (no caso dos pelágicos demonstram também o impacto da regra dos 100 dias, uma vez que em vários anos há mais pelágicos aparentemente desembarcados por aiolas que por botes).

Uma informação relevante sobre tendências ecológicas numa escala temporal mais alargada foi inesperadamente obtida através duma pergunta de governança, construída com o objectivo de avaliar o conflito dos pescadores com a entidade gestora do PMLS. Este indicador de governança foi avaliado através da importância relativa atribuída a este conflito relativamente a outros problemas que pudessem ser considerados graves para a pesca. Uma larga maioria dos pescadores $(15 / 23,65 \%)$ elencou como maior problema a poluição, com outros 6 pescadores a elegê-la como segundo maior problema. O conflito com a entidade gestora foi considerado o terceiro maior problema (13\% como primeiro e $17 \%$ como segundo), atrás do valor de venda do pescado ( $22 \%$ primeiro e $26 \%$ segundo) e só à frente da pesca furtiva. No pedido de justificação desta orde- 

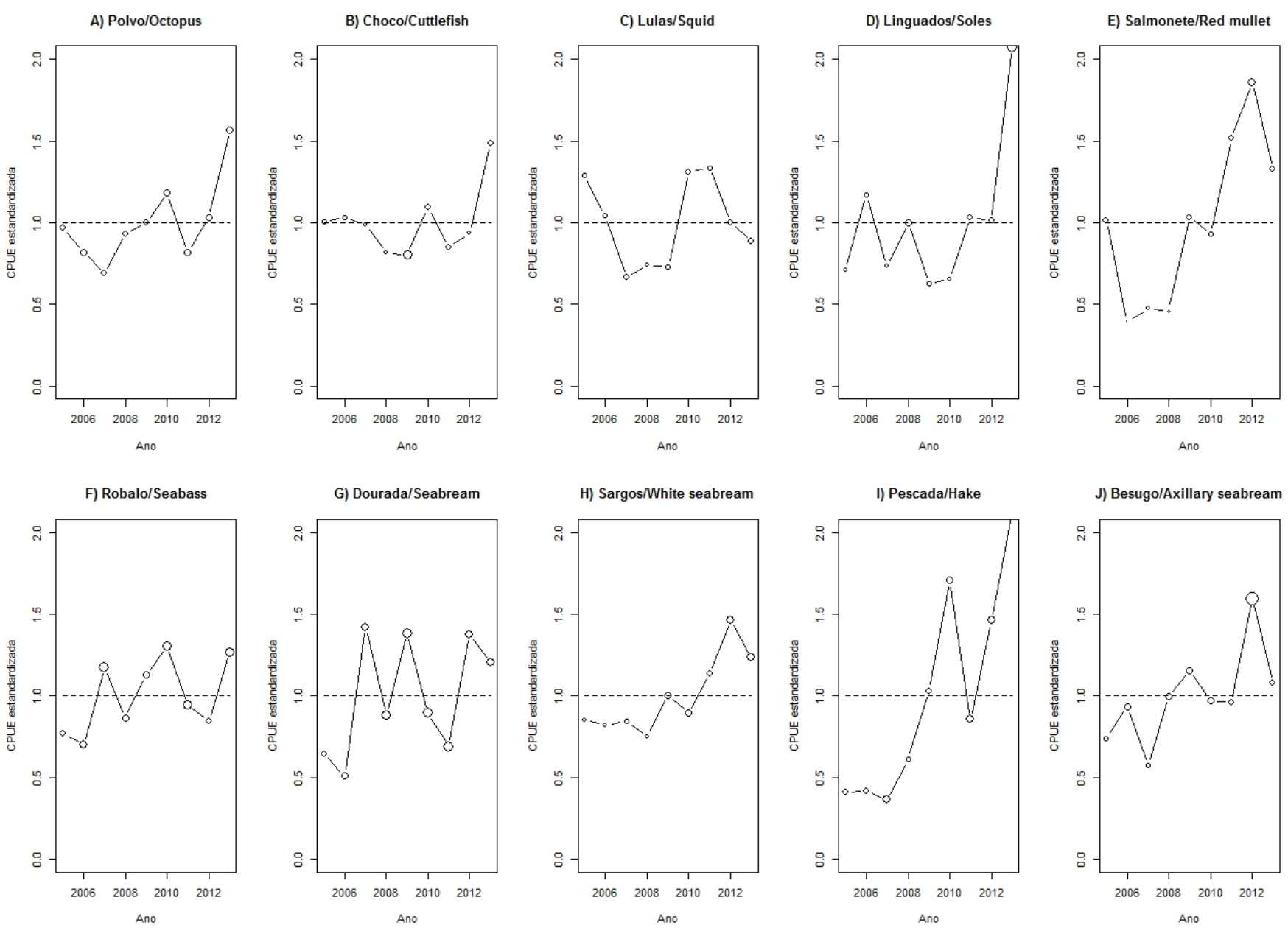

Figura 3 - Desembarque médio de espécies alvo por ida a lota (em kg por dia) para as embarcações do PMLS em cada ano no período 2005-2013. Valores são estandardizados sobre o desembarque médio neste período de 9 anos. Tamanho de símbolo é proporcional ao coeficiente de variação das observações em cada ano.

Figure 3 - Mean estimate of landing by auction register (in $\mathrm{kg}$ per day) for each target species of PMLS vessels in each year during the period 2005-2013. Values are standardised against the global mean over the 9 years period. Symbol size is proportional to the coefficient of variation for the observations in each year.

nação, o discurso invariavelmente identificou o desaparecimento repentino das macroalgas castanhas da costa de Sesimbra, algures no final dos anos 1980 ou o início dos anos 1990. No raciocínio dos pescadores este desaparecimento não pode ser relacionado com a pesca ou a apanha de algas, por ter sido repentino, só podendo ser explicado pela poluição. Apesar da variabilidade nas explicações oferecidas para a mais provável fonte desta "poluição", as opiniões convergiam para a percepção de que este desaparecimento trouxe uma redução de diversidade e produtividade, através da simplificação dos habitats costeiros que na altura das macroalgas castanhas abrigavam juvenis de várias espécies de peixe com interesse comercial e crustáceos valiosos (ver também Stratoudakis et al., 2015, para discurso similar dos outros utentes do PMLS).

\section{iii) Indicadores socioeconómicos e de governança}

Dos 23 pescadores inquiridos, 5 (22\%) não dependem exclusivamente da pesca para os seus rendimentos, sendo que para 3 deles a pesca é metade ou menos do rendimento total. Em relação ao valor da embarcação, quase todos assumiram que a embarcação valeria mais se pudesse ter a licença do PMLS incluída. Alguns só foram capazes de estimar um valor de potencial venda no caso de incluir a licença do PMLS ("sem a licença do parque não vale nada"), enquanto que a mediana de incremento de valor após inclusão da licença do PMLS foi em cerca de $22 \%$. Apesar deste aumento proporcional ser aproximadamente igual para embarcações a pescar totalmente e parcialmente dentro do PMLS, os valores totais atribuídos foram significativamente diferentes $(W=7,5, p<0,001)$ : a mediana do valor das embarcações a pescar parcialmente dentro do PMLS era 8 vezes superior à das que só pescam dentro do PMLS. Isto reflecte principalmente a diferença de tamanho, potência, investimento em equipamento e idade entre botes e aiolas, sendo que o valor estimado é correlacionado com a captura $(R h o=0,37 ; p=0,010)$ e fortemente correlacionado com a CPUE $($ Rho $=0,41$; 
$p=0,004)$ da espécie alvo identificada por cada pescador.

A maioria dos inquiridos conhecia pescadores que se viram forçados a abandonar zonas de pesca tradicionalmente usadas com a entrada em vigor do plano de ordenamento do PMLS. A grande maioria $(14 / 22,64 \%)$ considerou que os pescadores excluídos pelo POPNA foram maioritariamente pescar em outras áreas (como por exemplo os pescadores de Setúbal), mas houve também quem achasse que o mais frequente foi a procura de reforma $(23 \%)$ ou o desemprego por impossibilidade de se adaptar às novas condições de pesca (13\%). Foi também identificada uma minoria que modificou a sua actividade dentro do PMLS, saindo da pesca profissional para entrar na actividade marítimo-turística ou na pesca lúdica. Na opinião dos pescadores actualmente a pescar no PMLS, o principal motivo para
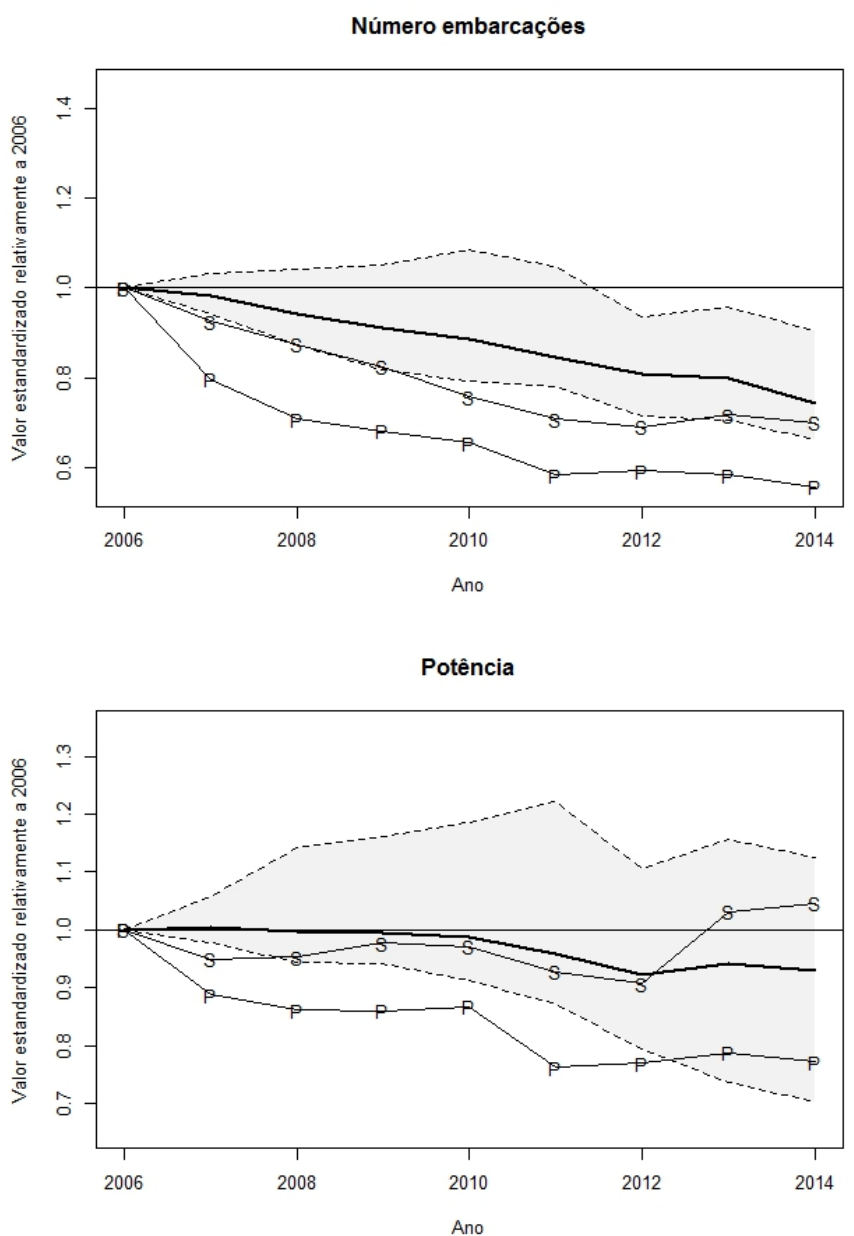

os pescadores excluídos do PMLS abandonarem a pesca profissional foi a possibilidade de reforma ou problemas de saúde $(7 / 23,30 \%)$, enquanto que $5(22 \%)$ consideraram directamente o PMLS como principal motivo de abandono (através da impossibilidade de transferir a licença em caso de reforma ou da ausência de espaço dentro do PMLS) e 3 indirectamente (através do aumento do custo da deslocação para pescar fora do PMLS). Por outro lado, 19 dos 23 inquiridos (83\%) conhecem pelo menos uma pessoa a querer obter a licença do PMLS, sendo que 13 (55\%) conhecem pelo menos 6-10 pescadores a querer obter esta licença.

Considerando os dados oficiais da actividade pesqueira no período desde a introdução das regras do PMLS, verifica-se que, em 2014, as embarcações com licença do PMLS eram cerca de $60 \%$ das 113 embarcações inicialmente licenciadas em 2006 (Figura 4). Este
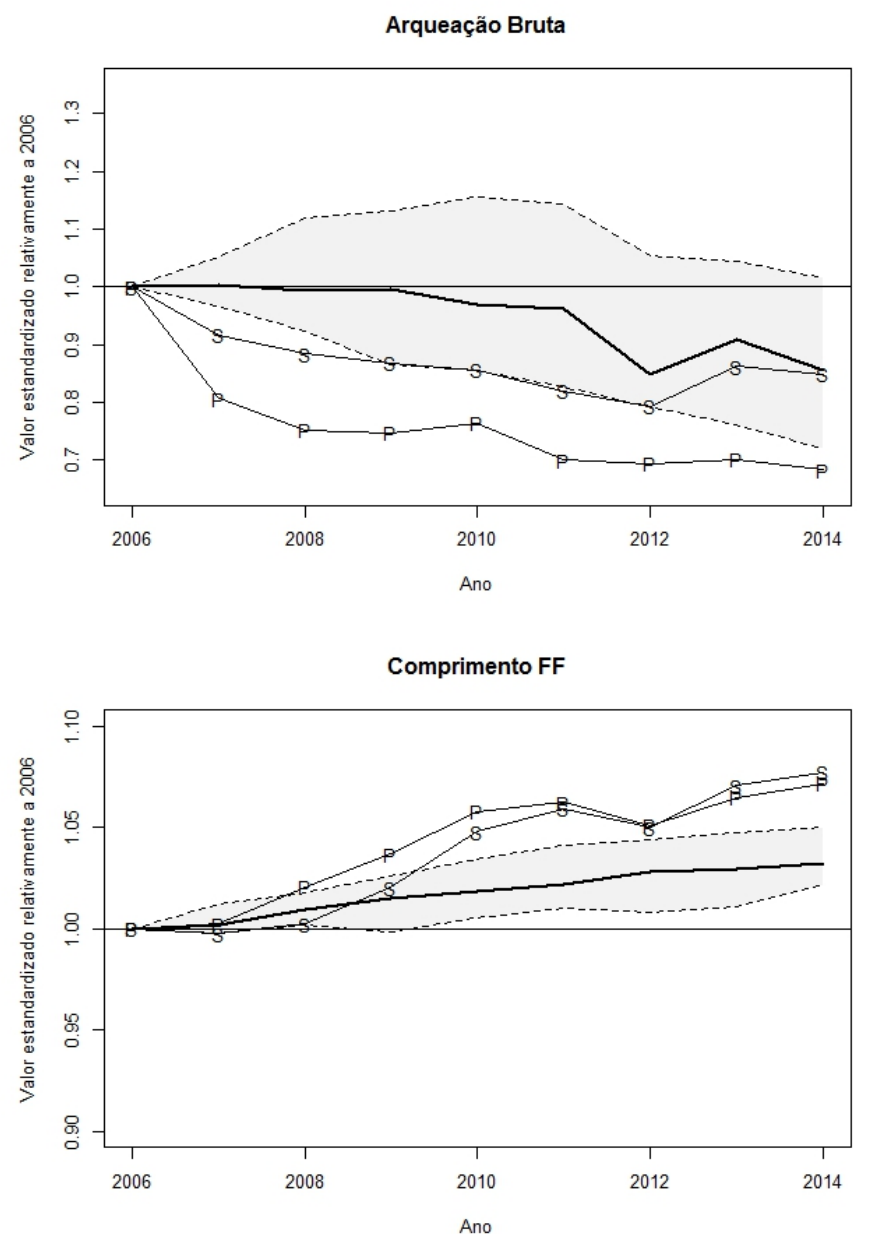

Figura 4: Evolução das características de embarcações com $<7 \mathrm{~m}$ nos 32 maiores portos de pesca em Portugal continental durante o período 2006-2014 (A: número de embarcações registadas e com licenças activas; B: arqueação bruta total; C: potência de motor total, KW; D: comprimento total médio, m). Valores por porto estandardizados ao valor de 2006 . Linha grossa continua: mediana; Linhas tracejadas: quartis 25\% e 75\%; Zona assombrada: região de intervalo interquartil; P: valores anuais no PMLS; S: valores anuais no porto de Sesimbra (incluindo as embarcações do PMLS e as não licenciadas).

Figure 4: Temporal evolution of $<7 \mathrm{~m}$ vessel characteristics in the 32 main fishing ports of continental Portugal during the period 2006-2014 (A: number of registered vessels with active fishing licenses; B: gross register tonnage (total); C: engine power (total); D: vessel length (mean, m). Values by port are standardised to the 2006 value. Thick continuous line: median; broken lines: $25 \%$ and $75 \%$ quartiles; Shadowed area: inter-quartile region; P: annual values in PMLS; S: annual values for the port o Sesimbra (including PMLS and non-licensed vessels). 
decréscimo foi relativamente menor para a arqueação bruta total (cerca de $70 \%$ do inicial) e ainda menor para a potência $(80 \%)$, uma vez que houve um abandono desproporcional de embarcações comparativamente mais pequenas (principalmente aiolas, algumas delas até sem motor) que contribuiu também para o progressivo aumento do comprimento médio das embarcações.

Pelos dados apresentados pode também se deduzir que só uma parte das embarcações excluídas pelo PMLS foram abatidas ou desactivadas, uma vez que a redução para o porto de Sesimbra neste período é menor do que para o PMLS (acompanhando aproximadamente o limite inferior do intervalo interquartil dos 32 portos de pesca mais importantes em Portugal continental). Desde 2013 parece também ter havido uma inversão de tendência, com um aumento no número de embarcações de pesca legalmente registadas no porto de Sesimbra mas sem licença do PMLS. Esta entrada de novas embarcações resultou também num aumento de arqueação e de potência (passando em média de $4 \mathrm{KW}$ em 2006 para $18 \mathrm{KW}$ em 2014), ao ponto que em 2014 a potência total das embarcações de Sesimbra com $<7 \mathrm{~m}$ é maior que em 2006, apesar da redução do número total de embarcações neste período em cerca de $20 \%$.

$\mathrm{Na}$ identificação dos principais conflitos com outros usuários da AMP, a grande maioria (16/23) priorizou conflitos de uso com outros pescadores (profissionais ou lúdicos) autorizados a operar no PMLS: $39 \%$ dos inquiridos identificaram os pescadores lúdicos e outros $30 \%$ os pescadores profissionais com outras artes como o principal motivo de conflito. Conflitos com pescadores furtivos (embarcações sem licença do PMLS provenientes de outros portos ou de pesca submarina) foram também assumidos ( 2 como primeiro problema e 6 como segundo), enquanto que os conflitos com outros utentes (principalmente mergulho) ou agências de fiscalização (policia marítima e vigilantes da natureza do ICNF) tiveram menor destaque. Isto reflecte-se também na priorização de problemas de gestão pesqueira não resolvidos dentro do PMLS, com $48 \%$ dos inquiridos a identificarem a predominância de algumas artes dentro do espaço do PMLS como o maior problema de gestão pesqueira na AMP. A pesca ilegal foi reconhecida como o segundo maior problema de gestão a resolver, mas com a ênfase nos pescadores furtivos externos ao PMLS $(57 \%$ dos inquiridos assumiram raramente ou nunca quebrar as regras do PMLS, mas houve $35 \%$ a admitir que quebrava alguma regra pelo menos quinzenalmente). Finalmente, a presença de demasiados barcos dentro do PMLS surgiu como terceiro problema e o excesso de rejeições como pouco importante.

Relativamente à criação de conhecimento, cerca de $60 \%(14 / 23)$ dos inquiridos afirmaram conhecer em média 2.8 projectos de investigação relacionados com o
PMLS, tendo participado de alguma forma em 1,6 deles (os restantes $40 \%$ assumiram não conhecer nenhum projecto). Todavia, só $26 \%$ (6/23) dos inquiridos reconheceram ter tido conhecimento dos resultados de qualquer projecto de investigação. Para o indicador de governança relacionado com o associativismo, $70 \%$ dos inquiridos tiveram conhecimento em média de 5.6 reuniões e participaram em 3,6 (os restantes 30\% não participaram em nenhuma reunião da AAPCS no último ano, com $17 \%$ nem sequer sendo sócios). Só $44 \%$ $(10 / 23)$ dos pescadores interveio alguma vez nas deliberações da Associação, em média 2,7 vezes por ano. A grande maioria dos inquiridos $(17 / 23,74 \%)$ reconhece que entre os papéis da AAPCS deve ser a deliberação e propostas para a gestão do PMLS, sendo que $30 \%$ considera isto como primeira prioridade (mas há um número semelhante de inquiridos a achar que a primeira prioridade da Associação deve ser a resolução de assuntos legais e pessoais dos associados). Finalmente, $65 \%(15 / 23)$ identifica como melhor modelo de governação para garantir a pesca sustentável dentro do PMLS a cogestão entre a actual entidade gestora do PMLS (ICNF) e os próprios pescadores.

Relativamente ao aconselhamento hipotético sobre actividade profissional a um membro jovem da sua família, 19 em 22 (86\%) recomendariam um emprego não ligado a pesca, seguido por um actividade ligada a pesca e só por último considerar ganhar a vida na pesca. Só $2(10 \%)$ escolheram pesca como primeira opção e 3 como segunda, enquanto que 1 não considerou sequer a pesca como opção. Relativamente à preferência pessoal para o futuro ( 5 cenários alternativos de actividade nos próximos 5 anos), praticamente ninguém quis ir para uma maior embarcação e pescar fora do PMLS (só um o considerou como terceira opção e um como ultima) e só dois consideraram a hipótese de encontrar outro emprego (um como primeira e outro como segunda opção). Cerca de um terço $(30 \%)$ consideraram a reforma, 2 como primeira opção e 5 como segunda, e quase metade $(44 \%)$ preferiram continuar na situação actual (6 como primeira opção e 4 como segunda). Todavia, a maioria (48\%) optou por escolher voltar às condições de pesca antes da entrada do PMLS, 10 como primeira opção e 1 como segunda. Houve também 4 pescadores (17\%) que mesmo sem a existência deste cenário no questionário identificaram como primeira opção uma situação intermédia entre a actual e a anterior à entrada em vigor das regras do PMLS (afirmações variaram desde "como antes, mas com regras" até "como é agora, mas com mais algum espaço para pescar").

\section{Conclusões}

A caracterização da pesca do PMLS com base nas respostas ao inquérito foi reveladora de uma maior com- 
plexidade da que normalmente é reconhecida para a actividade desta pequena frota de $<7 \mathrm{~m}$ (ver Cabral et al., 2008 para uma descrição detalhada da frota do PMLS e Horta e Costa et al., 2013b para uma caracterização comparativa da distribuição espacial das artes de pesca antes e depois da implementação do POPNA):

- Existem múltiplos métiers com zonas de operação variáveis (e provavelmente dinâmicas definidas em escalas espaciais distintas para as correspondentes espécies alvo): a pescada, o besugo, os tamboris, as raias e a corvina são principalmente capturados fora do PMLS, o polvo, o linguado, o congro, o robalo e a dourada tanto dentro como fora, enquanto que o choco, a lula, os sargos, a moreia e o salmonete são principalmente capturados dentro do PMLS;

- As diferenças de tipologia entre botes e aiolas (Cabral et al., 2008; Abecassis et al., 2013) resultam também em diferenças operacionais relacionadas com o grau de uso do PMLS na sua actividade regular (muito maior dependência do espaço do PMLS para as aiolas) e na CPUE por maré (significativamente inferior em quantidade e valor para as aiolas);

- O número total de licenças de artes de pesca disponíveis em cada embarcação é largamente superior ao número efectivamente utilizado (em sintonia com a situação no resto do país), não podendo actualmente constituir nem um indicador de actividade nem uma ferramenta de gestão do esforço pesqueiro;

- Apesar da predominância de espécies pelágicas ou semi-pelágicas nos desembarques do PMLS (nomeadamente cavala e carapau), estes recursos de baixo valor comercial não constituem alvo dos pescadores (que em algumas situações até procuram evitá-los para reduzir o tempo de limpeza e reparação das redes), gerando desperdício e enviesando os indicadores baseados em dados de capturas em lota (e.g. Fig. 4 em Cunha et al., 2014);

- As 17 espécies ou taxa superiores identificadas pelos pescadores como alvos na Tabela 2 , representam entre 73 e $91 \%$ do total do valor das 160 espécies ou taxa superiores desembarcados na lota de Sesimbra por embarcações do PMLS no período 2005-2013; isto indica que, na óptica dos pescadores, existe uma diferença substancial entre espécies passíveis de ser desembarcadas e espécies alvo e esta diferença deve ser tida em conta na análise da informação de monitorização por censos visuais no PMLS (que só incide sobre as espécies com presença em menor profundidade - e.g. Henriques et al., 2007; Horta e Costa et al., 2013a; Henriques et al., 2013 e que deve ser complementada com outro tipo de monitorização para as restantes espécies - e.g. através da pesca experimental com tresmalho iniciada no projecto BIOMARES - Cunha et al., 2014).
Os resultados obtidos pelos pescadores para os indicadores ecológicos no PMLS são inconclusivos, dada a ausência de padrões claros nas respostas e algumas incongruências com outras fontes de informação:

- Para o conjunto da actividade dos vários métiers, existe uma prevalência não significativa da percepção de algum declínio na CPUE das espécies alvo, mais evidente nas respostas dos que pescam exclusivamente dentro do PMLS (nomeadamente com toneira para lula e choco), que pode ser corroborada no caso da lula pelos dados oficiais de desembarque (enquanto que para a maioria das espécies da Tabela 1 apresentadas na Figura 3 a CPUE média em 2013 é superior à de 2005, para a lula é inferior) e teoricamente apoiada no caso do choco (pelo estudo do efeito reserva no PMLS com recurso a telemetria - Abecassis et al., 2013), mas em ambos os casos esta dinâmica é definida em escalas espaciais maiores que a do PMLS;

- Espécies para as quais os dados de lota (Fig. 3) e a literatura apontam para algum aumento nos desembarques recentes (pescada, como resultado do plano de recuperação do stock Ibérico - e.g. STECF, 2013; sargos como verificado na monitorização do PMLS - Horta e Costa et al., 2013a; e salmonete, como resultado da pesca experimental no PMLS licenciada nos primeiros 4 meses do ano desde 2011) não foram destacadas nas respostas dos pescadores;

- No caso dos linguados, ligeiros indícios de aumento recente nas respostas ao inquérito e nos dados de desembarques é teoricamente apoiada pelos resultados dum estudo recente de telemetria (que aponta para movimentos limitados dentro e perto da AMP Abecassis et al., 2014) mas não pela análise de CPUE experimental apresentada no mesmo trabalho;

- Existem algumas indicações de alterações para espécies não alvo, com os pelágicos a aumentar e a faneca a diminuir, que são corroboradas pelos dados de desembarques nos últimos anos (no caso dos pelágicos mesmo para embarcações locais fora do PMLS) e, no caso da cavala por literatura recente (e.g. Martins et al., 2013);

- Nos indicadores ecológicos de tendência, não houve percepção de alguma alteração na biodiversidade do sistema, no tamanho de predadores, na força de recrutamento de espécies alvo ou no spill-over de biomassa para fora do PMLS, podendo isto significar falta de melhoria no sistema ecológico do PMLS ou falta de adequação dos indicadores pesqueiros às propriedades do sistema a monitorizar (resultante de formulação inapropriada da pergunta ou falta de informação adequada na resposta - e.g. o número de espécies capturadas por ano estimado nas respostas é substancialmente inferior ao observado por arte em Cabral et al., 2008); 
- A observação mais relevante para a biodiversidade e produtividade da zona ocorreu indirectamente (através das respostas a uma pergunta de governança) que revelou a importância do desaparecimento das macroalgas castanhas antes da delimitação do PMLS, tanto na estrutura e funcionamento ecológico do sistema (e.g. Santos, 1993; Ramos, 2009) como na aceitação do PMLS (por causa da lembrança de um sistema ecológico rico e diverso sem as restrições do POPNA).

Os resultados obtidos para os indicadores socioeconómicos e de governança são claros no registo maioritário de desalento, mas difusos no registo das causas e propostas de solução:

- Prevalece uma insatisfação com a situação actual de pesca no PMLS (maioria quer voltar à situação anterior ao PMLS ou modificar as regras actuais) e pessimismo sobre o futuro (quase ninguém recomenda a pesca para o futuro de jovens familiares), posições que, apesar da provável influência das tendências gerais na pequena pesca em Portugal (Fig. 4) e no sul da Europa (e.g. Freire and Garcia-Allut, 2000; Garcia-de-la-Fuente et al., 2013), contêm também alguns elementos específicos da realidade do PMLS (e.g. vontade de mudar para condições antes do PMLS significativamente maior para aiolas do que para botes; as mesmas perguntas nas AMPs de Cedeira e Lira na Galiza tiveram respostas mais optimistas - Vidal e Verisimo, per. com.);

- Apesar da falta de detecção de melhorias ecológicas com influência na actividade pesqueira nos anos recentes, identifica-se um número razoavelmente elevado de pescadores a querer obter a licença do PMLS (juntamente com o surgimento de embarcações $<7 \mathrm{~m}$ mais potentes em Sesimbra sem licença do PMLS) e há reconhecimento de algum valor económico especificamente atribuído na licença do PMLS (que possivelmente é mais ligado à proximidade ao porto de origem, principalmente no caso das aiolas - Horta e Costa et al., 2013b);

- Os maiores problemas de gestão pesqueira são relacionados com a concorrência pela ocupação do espaço por actividades de pesca autorizadas no PMLS (lúdicos e profissionais), mas apesar dos problemas e da vontade de alterações, o conflito com a entidade gestora (ICNF) não é assumido como forte ou a deteriorar. A opção de cogestão com o ICNF é largamente prevalecente, o que é consistente com uma vontade de maior participação na governança do sistema (Carneiro, 2011; Vasconcelos et al., 2012) mas não com a visão de uma considerável fração dos inquiridos que entende que a principal função da Associação deve ser de resolver problemas pessoais dos pescadores;

- Existem grandes diferenças entre aiolas e botes em termos de licenças, rendimentos, perspectivas para o futuro que se agravem com o passar dos anos desde a implementação do POPNA.

\section{Appendix}

Supporting Information associated with this article is available on-line at http://www.aprh.pt/rgci/pdf/rgci571_Stratoudakis_Supporting-Information.pdf

\section{Agradecimentos}

Este trabalho teve o apoio e colaboração de um elevado número de pessoas. Devemos cronologicamente destacar:

$>$ A AAPCS (através dos seus presidentes Arsénio Caetano e António Pila) pelo acompanhamento geral do projecto MAIA e o apoio operacional deste estudo;

$>$ Carina Reis (AAPCS) pela sugestão original de pedir informação sumária para fins de monitorização directamente aos pescadores;

$>$ Juan Freire, Inma Alvarez e Nuria Fernandez (Universidade de Corunha) e Cristina Pita (Universidade de Aveiro) pelo contributo na realização do workshop que levou ao desenvolvimento da metodologia;

> Isabel Costa (DGRM) e Joaquim Piló (Sindicato Livre dos Pescadores) pela ajuda na formulação das perguntas;

$>$ Nair Franco (AAPCS) pelo apoio logístico na amostragem e entrevistas;

$>$ Pescadores PMLS pela participação no inquérito;

$>$ Cristina Rosa e Teresa Taborda (DGRM) pelo fornecimento de dados sobre a actividade pesqueira em Portugal continental;

$>$ Duarte Vidal e Patricia Verisimo (Universidade de Corunha) pelas informações na aplicação do mesmo questionário nas AMPs de Cedeira e Lira na Galiza;

$>$ Catarina Grilo (Fundação Gulbenkian) e Paulo Oliveira (IPMA) pela leitura crítica do manuscrito.

Este trabalho foi desenvolvido no âmbito do projecto MAIA (INTERREG IVB-Espaço Atlântico, 2009-1/143).

\section{References}

Abecassis, D.; Afonso, P.; O’Dor R.K.; Erzini, K. (2013) - Small MPAs do not protect cuttlefish (Sepia officinalis). Fisheries Research, 147:196-201. DOI: 10.1016/j.fishres.2013.05.004

Abecassis, D.; Afonso, P.; Erzini, K. (2014) - Can small MPAs protect local populations of a coastal flatfish, Solea senegalensis? Fisheries Management and Ecology, 21(3):175-185. DOI: 10.1011/fme.12061

Batista, M.I.; Baeta, F.; Costa, M.J.; Cabral, H.N. (2011) - MPA as management tools for small-scale fisheries: the case-study of Arrábida Marine Protected Area (Portugal). Ocean and Coastal Management, 54:137-147. DOI: 10.1016/j.ocecoaman.2010. 10.032

Cabral, H.N.; Batista M.; Baeta, F.; Alves, A.; Costa, M.J. (2008) Avaliação do impacto das condicionantes na Área Marinha do Parque Natural de Arrábida à actividade da pesca comercial e lúdica, a náutica de recreio e ao mergulho. Relatório Final. Instituto de Oceanografia, FCUL, Lisboa, Portugal. 242 pp + anexos. Não publicado.

Carneiro, G. (2011) - The Luiz Saldanha Marine Park: an overview of conflicting perceptions. Conservation and Society, 9(4): 325333. DOI: $10.4103 / 0972-4923.92149$

Coll, M., Carreras, M., Ciércoles C., Cornax, M.J., Gorelli, G., Morote, E. Sáez, R. (2014) - Assessing fishing and marine bio- 
diversity changes using fishers' perceptions: the Spanish Mediterranean and Gulf of Cadiz case study. PLOS One, 9(1): e85670. DOI: 10.3071/journal.pone.0085670

CPAS (1965a) - "Parques nacionais submarinos" num futuro muito próximo. Boletim do Centro Português de Actividades Submarinas, III(10):1-2, Lisboa, Portugal.

CPAS (1965b) - Parques nacionais submarinos: constituída a comissão de estudo. Boletim do Centro Português de Actividades Submarinas, III(11):15, Lisboa, Portugal.

Cruz, M.A. (1966) - Pesca e pescadores de Sesimbra. Contributo para a narrativa do conselho. Câmara Municipal de Sesimbra. ISBN: 978-972-9150-89-0

Cunha, A.H., Erzini, K., Serrão, E.A., Gonçalves, E., Borges, R., Henriques, M., Henriques, V., Guerra, M., Duarte, C., Marbá, N., Fonseca, M. (2014) - Biomares, a LIFE Project to restore and maange the biodiversity of Prof. Luiz Saldanha Marine Park. Journal of Coastal Conservation. 18:643-655. DOI: 10.1007/s11852-014-0336-x

Davis, A.; Wagner, J.R. (2003) - Who knows? On the importance of identifying "experts" when researching local ecological knowledge. Human Ecology, 31(3):463-489.

Freire, J., Garcia-Allut, (2000) - Socioeconomic and biological causes of management failures in European artisanal fisheries: the case of Galicia (NW Spain). Marine Policy, 24(5):375-384. DOI: 10.1016/S0308-597X(00)00013-0

García-de-la-Fuente, L.; González-Álvarez, J.; García-Flórez, L.;Fernández-Rueda, P.; Alcazár-àlvarez, J. (2013) - Relevance of socioeconomic information for the sustainable management of artisanal fisheries in South Europe. A characterization study of the Asturian artisanal fleet (northern Spain). Ocean and Coastal Management, 86:61-71. DOI: 10.1016/j.ocecoaman.2013.05.007

Henriques, M.; Gonçalves, E.J.; Almada, V.C. (2007) - Rapid shifts in a marine fish assemblage follow fluctuations in winter sea conditions. Marine Ecology Progress Series, 340:259-270.

Henriques, S.; Pais, M.P.; Costa, M.J.; Cabral, H.N. (2013) - Seasonal variability of rocky fish assemblages: detecting functional and structural changes due to fishing effort. Journal of Sea Research, 79:50-59. DOI: 10.1016/j.seares.2013.02.004

Horta e Costa, B.; Erzini, K.; Caselle, J.E.; Folhas, H.; Gonçalves, E. (2013a) - "Reserve effect" within a temperate marine protected area in the North-eastern Atlantic (Arrábida Marine Park, Portugal). Marine Ecology Progress Series, 481:11-24. DOI: 10.3354/meps 10204

Horta e Costa, B.; Batista, M.; Gonçalves, L.; Erzini, K.; Caselle, J.E.;, Cabral, H.N.; Gonçalves, E. (2013b) - Fishers' behaviour in response to the implementation of a marine protected area. PLOS1, 8(6): e65057. DOI: 10.1371/journal.pone.0065057

Jentoft, S., Pascual-Fernandez, J.P., Modino, R.C., GonzalezRamallal, M., Chuenpagdee, R. (2012) - What stakehodelrs think about marine protected areas: case studies from Spain. Human Ecology, 40:185-197. DOI: 10.1007/s10745-012-9459-6

Leleu, K., Alban, F., Pelletier, D., Charbonnel, E., Letourneur, Y., Boudouresque, C.F. (2012) - Fishers' perceptions as indicators of the performance of Marine protected Areas (MPAs). Marine Policy 36: 414-422. DOI: 10.1016/j.marpol.2011.06.002

Martins, M.M.; Skagen, D.; Marques, V.; Zwolinski, J.; Silva, A. (2013) - Changes in the abundance and spatial distribution of the Atlantic chub mackerel (Scomber colias) in the pelagic ecosystem and fisheries off Portugal. Scientia Marina, 77(4): 551563. DOI: 10.3989/scimar.03861.037B
McClanahan TR, Castilla JC, White AT, Defoe O (2009) Healing small-scale fisheries by facilitating complex socio-ecological systems. Reviews in Fish Biology and Fisheries, 19:33-47. DOI: 10.1007/s.11160-008-9088-8

Ostrom, E. (2009) - A general framework for analyzing socialecological systems. Science, 325:419-422. DOI: 10.1126/science. 1172133

Pollnac, R.; Christie, P.; Cinner, J.E.; Dalton, T.; Daw, T.M.; Forrester, G.E.; Graham, N.A.J.; McClanahan, T.R. (2010) Marine reserves as linked social-ecological systems. Proceedings of the National Academy of Science, USA, 107(43):1826218265. DOI: $10.1073 /$ pnas.0908266107

Pomeroy, R.S.; Parks, J.; Watson, L. (2004) - How is your MPA doing? A guidebook of natural and social indicators for evaluating marine protected areas and management effectiveness. IUCN, Gland, Switzerland and Cambridge, UK. Xvi +216 pp. ISBN: 2-8317-0735-8; 978-2-8317-0735-8. Available online at: https://portals.iucn.org/library/node/8417

Pomeroy, R.S.; Watson, L.M.; Parks, J.E.; Cid, G.A. (2005) - How is your MPA doing? A methodology for evaluating the management effectiveness of marine protected areas. Ocean and Coastal Management, 48:485-502. DOI: 10.1016/j.ocecoaman.2005.05.004

$\mathrm{R}$ Core Team (2014) - $R$ : A language and environment for statistical computing. R Foundation for Statistical Computing, Vienna, Austria. Available online at http://www.R-project.org/

Ramos M.J. (2009) - Memórias dos pescadores de Sesimbra: Santiago de Sesimbra no início dos anos 80 do século $X X$. Sociedade de Geografia de Lisboa. ISBN: 978-989-96308-0-2

Santos, A.J.F.R.; Azeiteiro, U.M.; Sousa, F.; Alves, F. (2012) - A importância dos conhecimentos e dos modos de vida locais no desenvolvimento sustentável: estudo exploratório sobre o impacto da Reserva Natural das Ilhas Berlengas (Portugal) na comunidade piscatória. Journal of Integrated Coastal Zone Management 12(4): 429-436. DOI: $10.5898 /$ rgci321

Santos, R. (1993) - A multivariate study of biotic and abiotic relationships in a subtidal algal stand. Marine Ecology Progress Series, 94:181-190.

Scientific, Technical and Economic Committee for Fisheries, STECF (2013) - I Review of scientific advice for 2014, Part 2 (STECF-13-11). Publications Office of the European Union, Luxembourg, EUR26902 EN, JRC 83564, 328 pp. Available online at http://stecf.jrc.ec.europa.eu/documents/43805/571417/201307 STECF+13-11+-+Review+of+advice+for+2014+Part+2 JRC83564.pdf

Stratoudakis, Y.; Fernándes, F.; Henriques, M.; Martins, J.; Martins R. (2015) - Situação ecológica, socioeconómica e de governança após a implementação do primeiro plano de ordenamento no Parque Marinho professor Luiz Saldanha (Arrábida, Portugal): II - percepções de utentes. Journal of Integrated Coastal Zone Management, $15(2): 167-172 . \quad$ DOI: 10.5894/rgci572

Yasué, M.; Kaufman, L.; Vincent, A.C.J. (2010) - Assessing ecological changes in and around a marine reserves using community perceptions and biological surveys. Aquatic conservation: Marine and Freshwater Ecosystems, 20(4): 407-418. DOI: 10.1002/acq. 1090

Vasconcelos, L.; Caser, U.; Pereira, M.J.R.; Gonçalves, G.; Sá, R. (2012) - MARGOV - Building social sustainability. Journal of Coastal Conservation, 16:523-530. DOI: 10.1007/s11852-0120189-0 